\title{
Comparative morphology of the forewing base articulation in Sternorrhyncha compared with a representative of Fulgoromorpha (Insecta, Hemiptera)
}

\author{
Barbara Franielczyk $^{1} \cdot$ Piotr Wegierek ${ }^{1}$
}

Received: 25 September 2015/Revised: 6 December 2015/Accepted: 8 December 2015/Published online: 22 December 2015

(C) The Author(s) 2015. This article is published with open access at Springerlink.com

\begin{abstract}
The forewing articulation of single species from each of the four subgroups of Sternorrhyncha (Aleyrodomorpha, Aphidomorpha, Coccomorpha, Psyllomorpha) was examined by optical and scanning electron microscopy. The species were compared with a species of Cixiidae (Fulgoromorpha), as an outgroup of Sternorrhyncha. We present the results of a comparative analysis of the forewing articulation in these five groups, propose a standardized terminology and compare our findings with those previously reported. The wing base of all examined species is composed of the following structures: anterior and posterior notal wing process, first, second, and third axillary sclerites, tegula, and axillary cord. The number of elements included in the wing base and the surrounding area is the greatest in Cacopsylla mali, the most complicated species from Sternorrhyncha. Based on the shape of axillary sclerites and the number of elements forming the wing base environment, Orthezia urticae (Coccomorpha) and Cixius nervosus (Fulgoromorpha) are the most similar. Among Sternorrhyncha, the most similar axillaries are those of Aphis fabae and Orthezia urticae, which is congruent with existing classifications. In this paper we show that the four groups from Sternorrhyncha exhibit their own distinct wing base morphology.
\end{abstract}

Keywords Forewing base - Axillary sclerites - Aphids . Coccids · Psyllids · Whiteflies

Communicated by A. Schmidt-Rhaesa.

Barbara Franielczyk

b.franielczyk@o2.pl

1 Department of Zoology, Faculty of Biology and Environmental Protection, University of Silesia, Bankowa 9, 40-007 Katowice, Poland

\section{Introduction}

The emergence of wings and ability to fly was a key to the evolutionary success of insects. Wing morphology was examined in an evolutionary context by Kukalovà-Peck (1978, 1991) and Rasnitsyn (1981), but most reports have tended to concentrate mainly on the course of veins (e.g. Comstock and Needham 1898; Hamilton 1972; Béthoux and Nel 2001, 2002; Béthoux 2007; Nel et al. 2011). The structure of the wing articulation in insects is a complex issue, which largely determines the ability to fly and its wing folding at rest (Chapman 2013). The flight issue was widely described by Wootton $(1996,2002)$ and Wootton and Kukalová-Peck (2000).

\section{General model of the wing articulation}

According to the diagram of the insect wing articulation (Snodgrass 1935), it usually consists of three main axillary sclerites (1Ax, 2Ax, 3Ax) [e.g. Hymenoptera and Orthoptera have a fourth axillary sclerite (4Ax) (Brodsky 1996) as also Aleyrodidae according to Weber 1935)] and the structures forming the environment of wing base. Two of these structures, the humeral plate and the tegula, constitute a connection between the wing base and the thorax. Moreover, the tegula, which is placed on each wing base (fore- and hindwing), has sensory hairs (Field and Matheson 1998). In this general model, the axillary sclerites $1 \mathrm{Ax}$ and $3 \mathrm{Ax}$ are connected to the body by lateral processes of the notum-the anterior notal wing process (anwp), the median notal wing process (mnwp) and the posterior notal wing process (pnwp) (Fig. 1). The first axillary is connected with anwp and mnwp and the third one with pnwp. The $1 \mathrm{Ax}$ and $2 \mathrm{Ax}$ are connected together. Proximal and distal median plates (pmp, dmp) can be found between the 


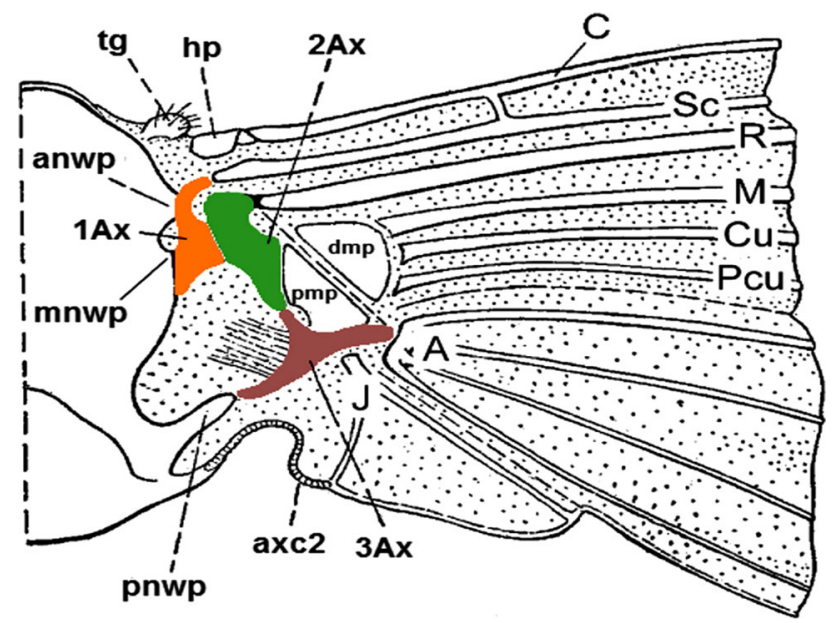

Fig. 1 Model of the insect wing articulation (after Snodgrass 1935, modified; abbreviations in the text)

wing membrane and axillary sclerites. The dmp is connected with three veins-media $(\mathrm{M})$, cubitus $(\mathrm{Cu})$ and cubitus posterior $\left(\mathrm{P}_{\mathrm{CU}}\right)$. The whole wing pivots on the fulcrum, the dorsal tip of the pleural wing process, which is connected with $2 \mathrm{Ax}$ and enables the wing movements (Snodgrass 1935). The connection between the scutellum and the wing base is enabled by the axillary cord (axc2). As suggested by Hörnschemeyer (2002), all structures that form the wing articulation, including the surrounding musculature, can be used in higher-level insect phylogenetics because the wing base structure is preserved at the genus or family levels.

\section{The structure of the forewing articulation among insects}

Many elements of the wing base are similar between the holo- and hemimetabolous insects. Within hemimetabolous insects, the wing base structure was recently examined in Hemiptera and Thysanoptera (Hörnschemeyer and Willkommen 2007), Odonata (Ninomiya and Yoshizawa 2009), and in the Dictyoptera (Yoshizawa 2011). Due to the small size of axillary sclerites, examination of the wing base has favored larger insects.

Within hemimetabolous Sternorrhyncha, there are a few studies on the course of wing veins (Patch 1909 and Klimaszewki and Wojciechowski (1993) in all Sternorrhyncha; Martin 2007 in whiteflies; Shcherbakov 2007 in aphids and coccids) and on the structure of the wings of coccids (Koteja 1996; Simon 2013).

The suborder Sternorrhyncha is divided into four infraorders: Psyllomorpha (jumping plant-lice) (BeckerMigdisova 1962), Aleyrodomorpha (whiteflies) (Chou 1963), Aphidomorpha (aphids) (Becker-Migdisova and
Aizenberg 1962) and Coccomorpha (scale insects) (Heslop-Harrison 1952). Some aphid and most psyllids and whiteflies adults have two pairs of wings, while in scale insects only males have well-developed wings, and only a single pair (Gullan and Martin 2009). Most Sternorrhyncha wing base studies focused on the dorsal side of the forewing Koteja (1996) in coccids, Weber $(1928,1929)$ in aphids, Yoshizawa and Saigusa (2001) and Ouvrard et al. (2008) in psyllids. The forewing articulation of whiteflies was examined in Aleyrodes proletella Linnaeus. 1758 and both the fore- and hindwing articulation was described in Trialeurodes vaporariorum Westwood 1856 (Weber 1935). The forewing base structure in Fulgoromorpha, a likely sister group to Sternorrhyncha (Song et al. 2012; Song and Liang 2013) was studied by Emeljanov (1977) and Yoshizawa and Saigusa (2001).

We undertook a study (1) to re-describe and compare the forewing articulations among the representatives of Sternorrhyncha using optical and scanning electron microscopy, (2) to compare the obtained results to a representative of Fulgoromopha, (3) to compare our results with the conclusions of previous authors, and (4) to unify the terminology.

\section{Materials and methods}

Sternorrhyncha specimens examined were of Cacopsylla mali (Schmidberger 1836) (Psyllomorpha), Aphis fabae Scopoli 1763 (Aphidomorpha), Orthezia urticae (Linnaeus 1758) (Coccomorpha), Aleyrodes proletella (Linnaeus 1758) (Aleyrodomorpha), with the sister-group represented by Cixius nervosus (Linnaeus 1758) (Cixiidae, Fulgoromorpha) (Table 1). These species belong to genera nominal for examined groups. The terminology of wing axillary sclerites and associated structures of the notum and pleuron follows Ouvrard et al. (2008). Additionally, Table 3 provides correspondence with the older studies of Weber (1928, 1929, 1935), Emeljanov (1977), Koteja (1986), Yoshizawa and Saigusa (2001).

Dry or ethanol-preserved (70\%) specimens were used. For SEM analysis, the entire insects were mounted on holders and sputter-coated with gold and examined using a scanning electron microscope Hitachi UHR FE-SEM SU 8010 (Tokyo, Japan) in the Scanning Electron Microscopy Laboratory at the Faculty of Biology and Environmental Protection, University of Silesia. The ventral part of the body, hind wings and legs were removed to facilitate observations in the light microscope. A Nikon SMZ1500 stereomicroscope was used to observe insects in glycerin. Specimens of $O$. urticae were first stained with chlorazol black following the procedure of Afifi and Kosztarab 
(1967). The orientation of described structures is in relation to the main axis of the body.

The abbreviations used in the text and in the figures: anwp-anterior notal wing process; $1 \mathrm{Ax}, 2 \mathrm{Ax}, 3 \mathrm{Ax}, 4 \mathrm{Ax}-$ axillary sclerites 1, 2, 3, 4; axc2-axillary cord; brbasiradiale; brb_basiradial bridge; bsc_-basisubcostale; dmp-distal median plate; hp-humeral plate; $\mathrm{m}$ mesonotum; mnwp-median notal wing process nt 1 pronotum; pmp—proximal median plate; pnwp-posterior notal wing process; ppt—parapterum; prb_-prealar bridge; psc2-praescutum; pwp-posterior wing process; sc2mesoscutum; scl2-mesoscutellum; tg-tegula.

\section{Results}

The structure of the wing base in the examined species is described below. The differences between the studied species are summarized in Table 2. A standardized terminology is given in Table 3 .
Cacopsylla mali (Figs. 2a, 3a, 5a, 6a)

The pronotum (nt1) does not reach the wing base.

The praescutum (psc2), mesoscutum (sct2) and mesoscutellum ( $\mathrm{scl} 2)$ are visible. The praescutum (psc2) laterally forms a small, globular extension, a prealar bridge (prb).

The wing base is articulated with the mesonotum by two processes: the upper one, anterior notal wing process (anwp) and the lower one, posterior notal wing process (pnwp) (Fig. 5a).

Two bulge-like structures are visible under prb: a bigger parapterum (ppt) and a smaller tegula (tg). Both are covered with a few small hairs (Figs. 3a white arrows, 5a).

The ligament-like axillary cord (axc2) runs laterally, parallel to the scutum (Fig. 2a).

The forewing articulation consists of three axillaries (Fig. 5a).

The first axillary sclerite articulates with the anterior notal wing process by an indentation on the top of its anterior arm (a), runs along the lateral edge of scutum and

Table 1 List of examined species

\begin{tabular}{|c|c|c|c|}
\hline Species & Locality & Host plant & Determination data \\
\hline $\begin{array}{l}\text { Aphis fabae } 20 \text { alate } \\
\text { females }\end{array}$ & $\begin{array}{l}\text { Piekary Śląskie, Poland } \\
\text { Bytom, Poland }\end{array}$ & $\begin{array}{l}\text { Chenopodium sp. Cirsium } \\
\text { arvense }\end{array}$ & $\begin{array}{l}\text { leg. B. Franielczyk, Silesia University det. Ł. Depa, Silesia } \\
\text { University }\end{array}$ \\
\hline $\begin{array}{l}\text { Aleyrodes proletella } 20 \\
\text { females }\end{array}$ & Piekary Śląskie, Poland & Chelidonium majus & $\begin{array}{l}\text { leg. B. Franielczyk, Silesia University det. J. Drohojowska, } \\
\text { Silesia University }\end{array}$ \\
\hline $\begin{array}{l}\text { Cacopsylla mali } 20 \\
\text { females }\end{array}$ & $\begin{array}{l}\text { Goczałkowice, Poland } \\
\text { Ustroń, Poland }\end{array}$ & Malus sp. & $\begin{array}{l}\text { leg. B. Franielczyk, Silesia University det. J. Drohojowska, } \\
\text { Silesia University }\end{array}$ \\
\hline $\begin{array}{l}\text { Orthezia urticae } 20 \\
\text { males }\end{array}$ & Goczałkowice, Poland & Urticae dioica & $\begin{array}{l}\text { leg. B. Franielczyk, Silesia University det. E. Simon, } \\
\text { Silesia University }\end{array}$ \\
\hline $\begin{array}{l}\text { Cixius nervosus } 10 \\
\text { females }\end{array}$ & $\begin{array}{l}\text { Libusza, Poland } \\
\text { Gładyszów, Poland }\end{array}$ & Xerothermic grasslands & $\begin{array}{l}\text { leg. M. Walczak, Silesia University det. M. Walczak, } \\
\text { Silesia University }\end{array}$ \\
\hline
\end{tabular}

Table 2 Elements of the wing base and their presence in the examined species from Sternorrhyncha and in $C$. nervosus

\begin{tabular}{|c|c|c|c|c|c|}
\hline Structure & Cacopsylla mali & Aphisfabae & Orthezia urticae & Aleyrodes proletella & Cixius nervosus \\
\hline anwp & + & + & + & + & + \\
\hline mnwp & & & & & + \\
\hline pnwp & + & + & + & + & + \\
\hline $1 \mathrm{Ax}$ & + & + & + & + & + \\
\hline $2 A x$ & + & + & + & + & + \\
\hline $3 A x$ & + & + & + & + & + \\
\hline $\operatorname{tg}$ & + & + & + & + & + \\
\hline hp & + & + & + & + & \\
\hline bsc & + & & & & \\
\hline br & + & & & & \\
\hline $\mathrm{dmp}$ & + & + & & + & \\
\hline pmp & + & & & & \\
\hline prb & + & & & & \\
\hline brb & + & & & + & \\
\hline $\mathrm{ppt}$ & + & & + & & \\
\hline $\operatorname{axc} 2$ & + & + & + & + & + \\
\hline
\end{tabular}




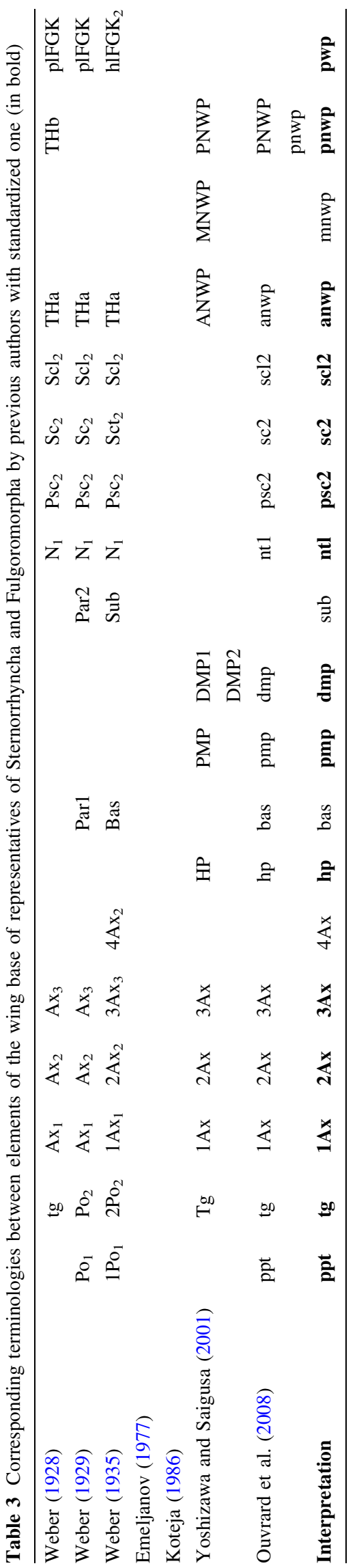

by its posterior arm (b), adjoins the second axillary sclerite (Fig. 3a).

The second sclerite also articulates with the anwp. The posterior part of this sclerite has the shape of acetabulum and is directed to the main wing vein $(\mathrm{R}+\mathrm{MP}+\mathrm{CuA})$ (Fig. 5a). 1Ax is almost entirely hidden by the second sclerite.

The first sclerite is triangular, with more sclerotized margins, while the second one is L-shaped (Fig. 6a). The central part of each sclerite is filled with membrane, which is also more or less sclerotized than the margins. $3 \mathrm{Ax}$ is curved in shape and strongly sclerotized halfway, the remaining area is membranous (Fig. 6a).

The third axillary sclerite adjoins pnwp (Fig. 5a).

Another extension, called humeral plate (hp), is visible below the tegula (Fig. 3a). This structure is fused with the basisubcostale (bsc), the proximal end of the costal + subcostal $(\mathrm{C}+\mathrm{Sc})$ vein, which is situated below.

The bsc is connected with the basiradiale below (br), situated on the basal part of the radial vein.

The connection between $2 \mathrm{Ax}$ and $\mathrm{R}+\mathrm{MP}+\mathrm{CuA}$ (=traditional $\mathrm{R}+\mathrm{M}+\mathrm{Cu}$ ) vein is provided by a basiradial bridge (brb), which covers the basiradiale.

A small, rounded distal median plate (dmp) is located below brb; it has visible proximal median plate ( $\mathrm{pmp}$ ) on its proximal edge (Fig. 3a).

\section{Aphis fabae (Figs. 2b, 3b, 5b, 6b)}

Pronotum (nt1) does not reach the wing base (Fig. 2b).

Prescutum, mesoscutum and mesoscutellum are visible.

The anterior notal wing process (anwp) and the posterior one (pnwp) are present (Fig. 5b).

The globular tegula and flat humeral plate are visible and the first one in covered with short hairs (Fig. 3b, white arrows).

Parapterum is not present.

The distal median plate, almost triangular in shape, is clearly visible (Fig. 3b).

A ligament-like axillary cord (axc2) runs laterally, parallel to the scutum (Fig. 2b).

1 Ax has two long arms, the anterior one (a) runs along the notum, connects with anwp and is directed to sclerotized subcostal vein, which it finally joins and the posterior arm (b) connects with $2 \mathrm{Ax}$ (Fig. 3b). This sclerite is longitudinal, adjacent to $1 \mathrm{Ax}$.

The last sclerite, $3 \mathrm{Ax}$, is slightly twisted and directed to the body with a forked end (Figs. 5b, 6b).

\section{Orthezia urticae (Figs. 2c, 3c, 5c, 6c)}

Pronotum (nt1) does not reach the wing base (Fig. 2c). Prescutum, mesoscutum and mesoscutellum are visible. 

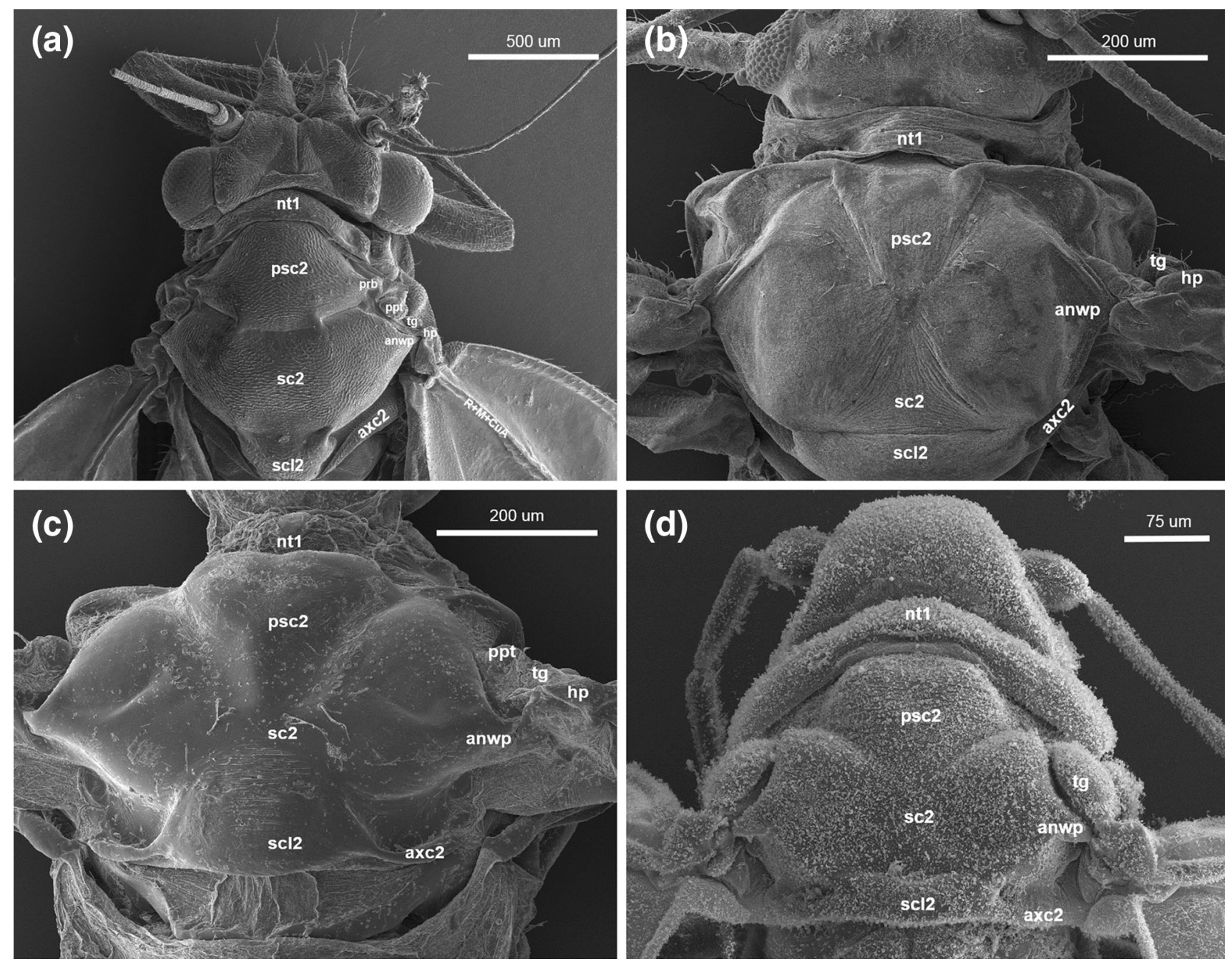

Fig. 2 Scanning electron microscopy showing the thorax of a Cacopsylla mali (Schmidberger 1836), b Aphis fabae (Scopoli 1763), c Orthezia urticae (Linnaeus 1758), d Aleyrodes proletella (Linnaeus 1758), dorsal view

The anterior notal wing process (anwp) is clearly visible and joins $1 \mathrm{Ax}$ (Fig. 3c).

The posterior notal wing process (pnwp) is present but visible only when the wings are raised.

The anterior structure called parapterum (ppt) is almost entirely hidden by tegula.

The tegula resembles a roofing tile and slightly covers forewing articulation. It is covered with a few hairs (Fig. 3c, white arrows).

The humeral plate is present distally (Fig. 3c).

The axillary cord runs parallel to the scutum (Fig. 2c).

Axillaries are more or less triangular in shape but sometimes only in outline. $1 \mathrm{Ax}$ has the shape of an equilateral triangle and its anterior tip is curved around the anterior end of $2 \mathrm{Ax}$.

The second sclerite is less obviously triangular with four projections.
The first one is surrounded by $1 \mathrm{Ax}$, the second is directed toward subcostal vein, the third is connected to the wing membrane and the last one is directed to $3 \mathrm{Ax}$.

The third axillary sclerite, which is more isosceles triangle-like in shape, is twisted about $180^{\circ}$ in the proximal part when the wings are directed downwards (Figs. 5c, 6c). It is proximally connected with pnwp and distally with the anal vein.

\section{Aleyrodes proletella (Figs. 2d, 3d, 5d, 6d)}

Pronotum (nt1) almost reaches the wing base (Fig. 2d).

Prescutum, mesoscutum and mesoscutellum are visible (Fig. 2d).

1Ax articulates with anwp (Fig. 3d).

The posterior notal wing process is recognizable as a posterior articulation of $3 \mathrm{Ax}$ (Fig. 5d). 

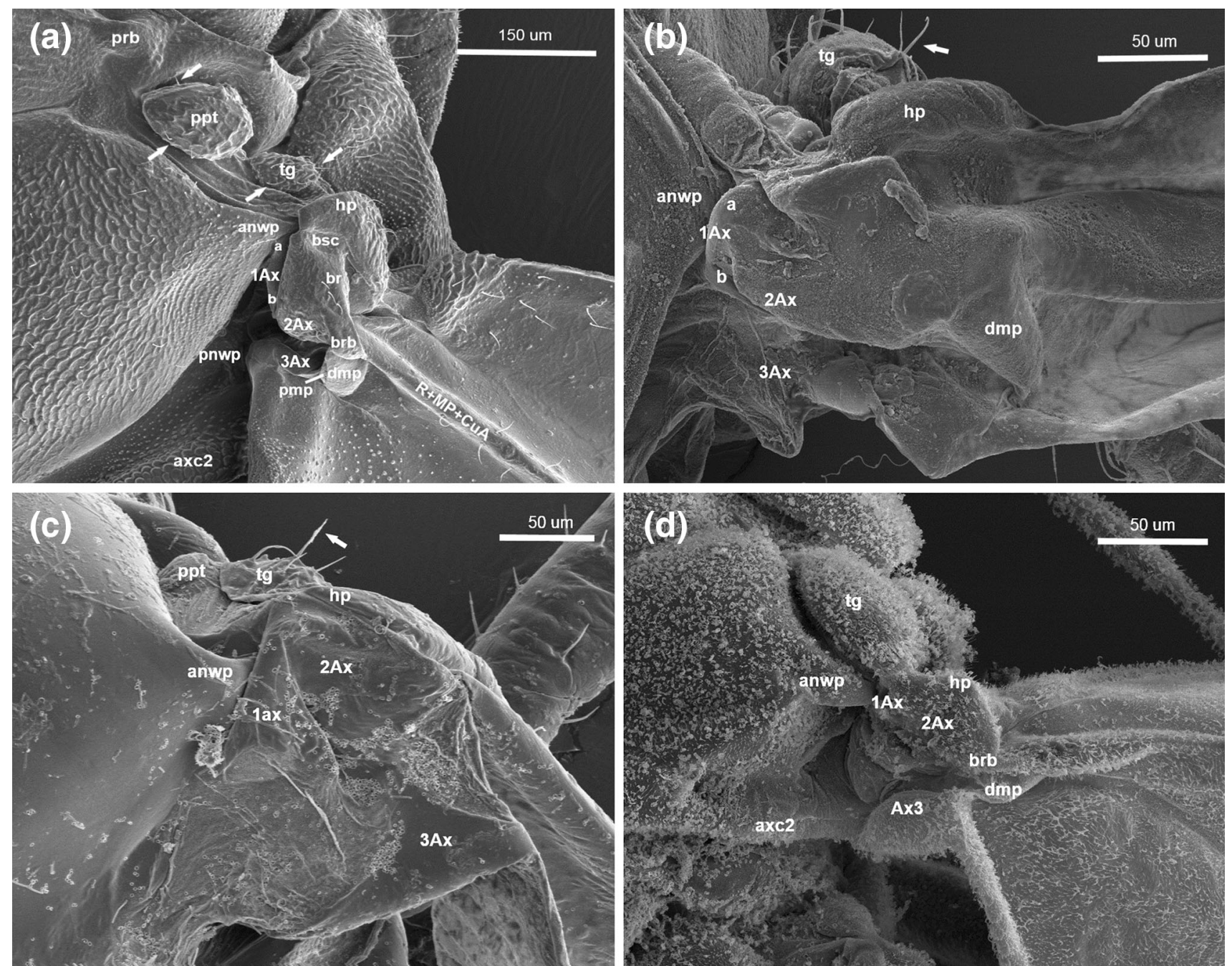

Fig. 3 Scanning electron microscopy showing the forewing articulation of a Cacopsylla mali (Schmidberger 1836), b Aphis fabae (Scopoli 1763), c Orthezia urticae (Linnaeus 1758), d Aleyrodes proletella (Linnaeus 1758), dorsal view; white arrows indicate hairs

Two external extensions, the tegula and the humeral plate, are visible. Tg is oval and well formed. Hp is a small plate below tg (Fig. 3d).

Parapterum is not present.

The basiradial bridge is located near the main wing vein (Fig. 3d).

There is a small, triangular extension below the basiradial bridge, probably the distal median plate (dmp).

The first axillary sclerite is the biggest, rather trapezoid in shape, with a small tip on the upper edge directed to the wing membrane. The body of $1 \mathrm{Ax}$ is connected to $2 \mathrm{Ax}$, the elongated sclerite directed toward the wing membrane.

The last one, 3Ax, is composed of an elongated body terminating with a triangle and having one triangular outgrowth in the middle. The ending is joined to $2 \mathrm{Ax}$ (Figs. 5d, 6d). There is a membranous element between the body and $3 A x$, which links these two elements and is adjacent to the posterior notal wing process (Fig. 5d).

\section{Cixius nervosus (Figs. 4a-c, 7b)}

Collar-shaped pronotum (nt1) is well developed and reaches down almost the forewing articulation (Fig. 4a).

Anwp joins $1 \mathrm{Ax}$ and pnwp is directed toward $3 \mathrm{Ax}$ (Fig. 4c).

The tegula is enlarged with a broad extension surrounding the entire outer margin of the wing base. Its surface is rather smooth with a few small hairs (Fig. 4b, white arrows). Parapterum is not present.

Axillary cord (axc2) runs parallel to the posterior edge of mesonotum (m).

1 Ax resembles a small trapezoid, with four clearly defined edges. The proximal edge is connected with anwp. Two distally located edges form a wall parallel to $2 \mathrm{Ax}$. The fourth one is directed to the process of notum, mnwp (Fig. 4c).

$2 \mathrm{Ax}$ has two arms; the longer but less sclerotized one (a) extends toward the wing membrane and the shorter but 

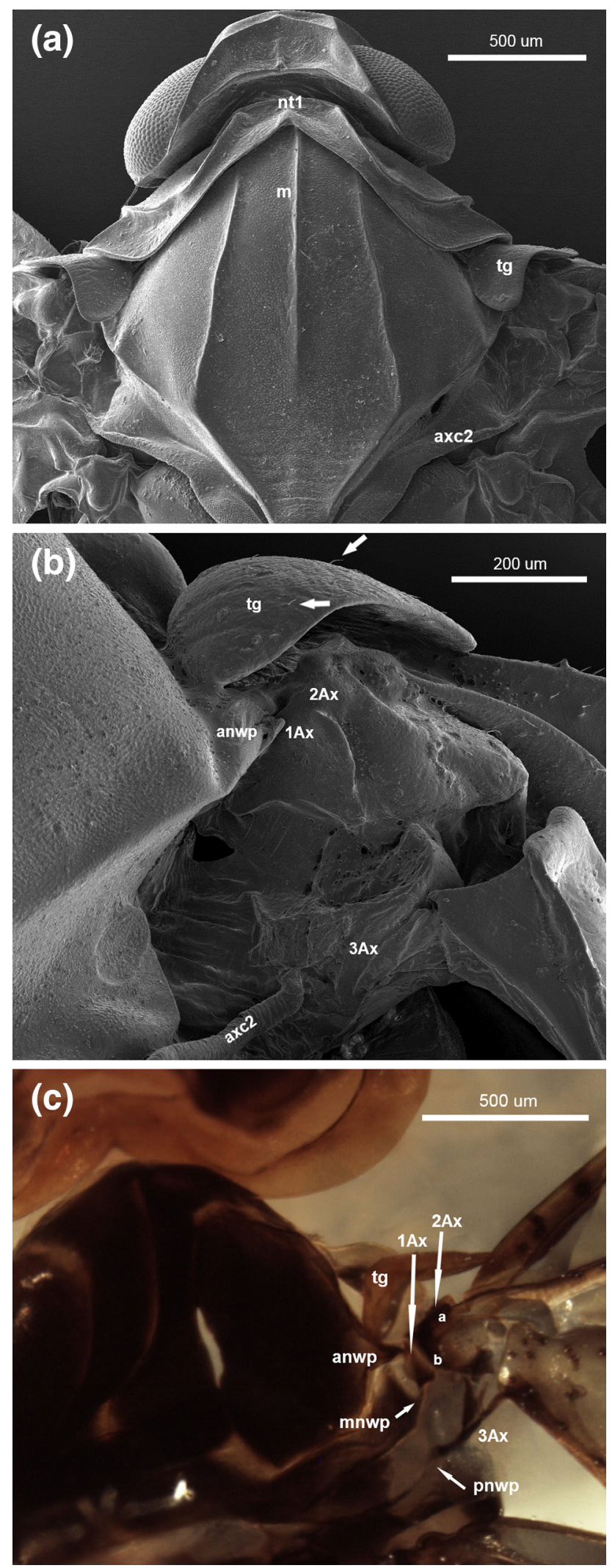

4Fig. 4 Scanning electron microscopy showing a the thorax of Cixius nervosus (Linnaeus 1758), $\mathbf{b}$ the forewing articulation of Cixius nervosus (Linnaeus 1758); optical microscopy showing $\mathbf{c}$ the forewing articulation of Cixius nervosus (Linnaeus 1758), dorsal view

more sclerotized one (b), with a forked end, is directed to the common stem of veins $\mathrm{ScP}+\mathrm{R}+\mathrm{MP}+\mathrm{CuA}$ (Fig. 4c). Between two arms of $2 \mathrm{Ax}$ a small indentation (a) is visible (Fig. 7b).

The third axillary sclerite is build of a longitudinal body with two outgrowths (Fig. 7b). The body of this sclerite is directed toward the claval edge of the wing distally and connects with the posterior notal wing process (pnwp) proximally (Fig. 4c).

\section{Discussion}

\section{Axillary sclerites}

The five examined species possess three axillary sclerites (1Ax, 2Ax, 3Ax). Differences concern mostly the shape of the sclerites. According to Weber (1935), in A. proletella $3 \mathrm{Ax}$ has two outgrowths, but the first, proximal one, is additionally forked. Our observations did not confirm that interpretation, and we also found a larger $2 \mathrm{Ax}$ than did Weber (1935). Our results for O. urticae were similar to those of Koteja (1986) with respect to all three axillary sclerites, with one exception: the position of the axillary sclerites was the same but only when the wing is directed downwards, as shown in Fig. 5c. In turn, in A. fabae, Weber (1928) described 1Ax as connected by its distal, upward curved end with an also curved ending of the subcostal vein and by its thickened distal part with $2 \mathrm{Ax}$. The second axillary sclerite was diamond-shaped and constituted a connection between $1 \mathrm{Ax}$ and $3 \mathrm{Ax}$. Our interpretation is similar: 1Ax has two arms, as was described earlier. The upper one is connected to the subcostal vein and the lower one to $2 \mathrm{Ax}$. The second axillary sclerite is more elongated in shape than diamond-like but lies very close to $1 \mathrm{Ax}$.

Emeljanov (1977), who described the overall pattern for Fulgoromorpha in general, presented $1 \mathrm{Ax}$ as an equilateral triangle (Fig. 7a) which in our opinion is more trapezoid in shape (Fig. 7b). But it is the second sclerite that proves most problematic. Emeljanov (1977) showed 2Ax as a sclerite composed of several fused elements (Fig. 7a). According to that author, the anterior part is formed by a humeral plate (hp), which is connected below to the basisubcostale (bsc). Two indentations are marked at this 

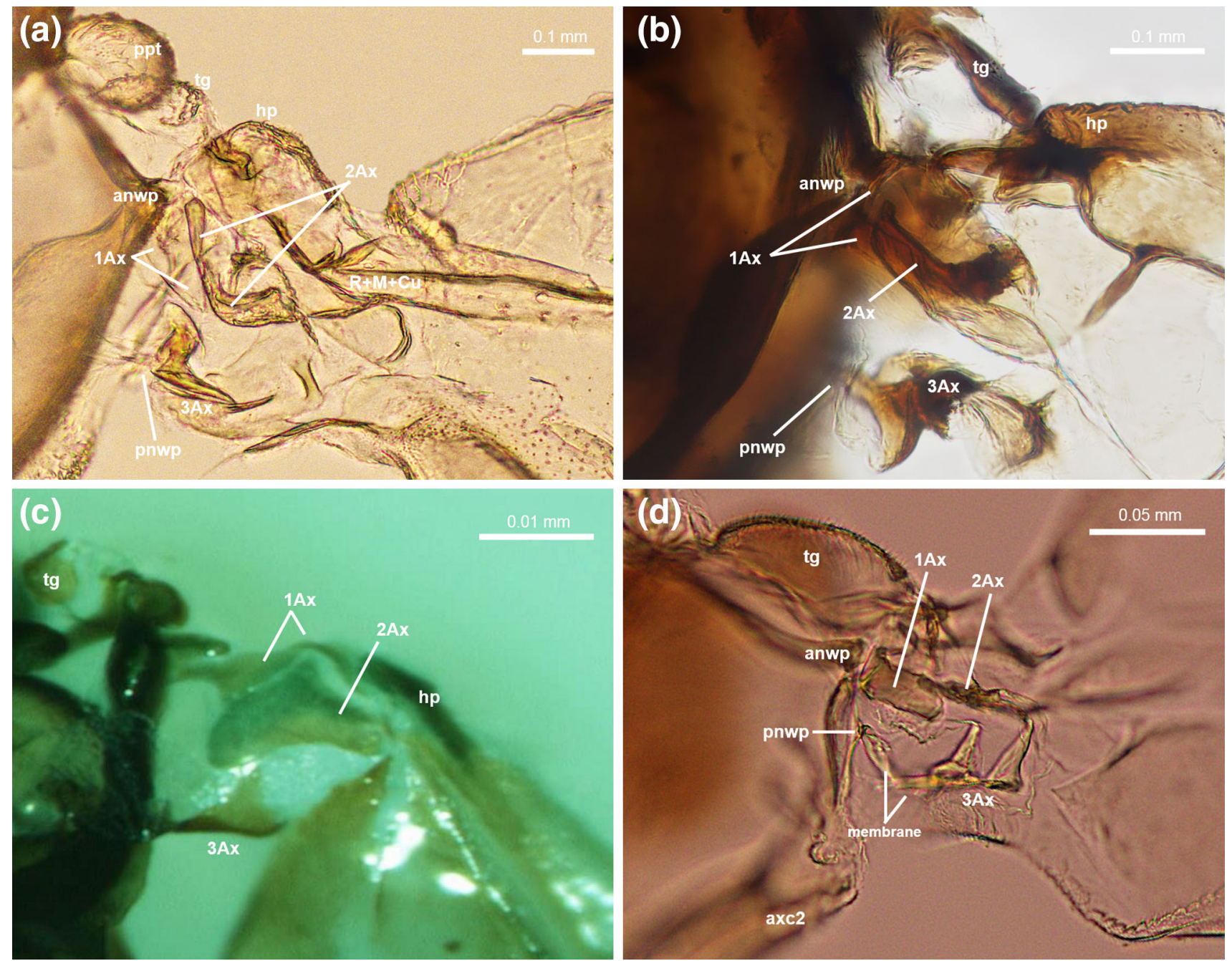

Fig. 5 Optical microscopy showing the forewing articulation of a Cacopsylla mali (Schmidberger 1836), b Aphis fabae (Scopoli 1763), c Orthezia urticae (Linnaeus 1758), d Aleyrodes proletella (Linnaeus 1758), dorsal view

location: proximal anterior (a) and distal posterior (b). The latter lies at the height of the $\mathrm{Sc}+\mathrm{R}+\mathrm{M}$ vein. Below, a wider part of the sclerite is composed of the element called $2 \mathrm{Ax}$ and of the median plate (mp), connected with the small triangular distal plate (md). Distally, 2Ax ends with a distal process (c), the connection with $3 \mathrm{Ax}$. The second axillary sclerite is connected with $1 \mathrm{Ax}$ by its straight anterior external edge. Yoshizawa and Saigusa (2001) described the second sclerite in Fulgoromopha as irregular and comprising a few elements: the upper, proximal part of $2 \mathrm{Ax}$ is fused with the basisubcostale and humeral plate without clear boundaries and the distal part passes smoothly into the distal median plate $(\mathrm{dmp}=\mathrm{md})$ and at the bottom almost links 3Ax and pmp (c). Authors did not mention about it, but we can point out the two indentations (a and b), which Emeljanov (1977) showed earlier (Fig. 7c). Our description of $2 \mathrm{Ax}$ is somewhat different (Fig. 7b), but agrees with Emeljanov's (1977) in the following: there is a proximal anterior indentation (a); also the posterior edge and a distal process (c) are clearly visible. Other elements cannot be distinguished because the rest of sclerite is membranous; only both arms of $2 \mathrm{Ax}$ are strongly sclerotized and easy to find in the wing articulation under the light microscope. Yoshizawa and Saigusa (2001) indicated that the third sclerite has a long body (d) extending from pnwp, with one branch facing $2 \mathrm{Ax}$. Another two elements connected to the sclerite body are basanale and pmp; however, they said that pmp is not always present. According to Emeljanov (1977), 3Ax has a short body (d) with two outgrowths (e, f), connected with $2 \mathrm{Ax}$ and one separated distal outgrowth $(\mathrm{g})$. The latter is directed toward the anal vein and connects to the jugal part of the wing membrane. Our results indicate that the $3 \mathrm{Ax}$ has a sharply pointed longitudinal body (d) and two appendages growing out of the sclerite body and rolled up in opposite directions. Both are directed toward $2 \mathrm{Ax}$ 
Fig. 6 Schematic drawing showing shapes and relations between axillary sclerites of the forewing articulation of a Cacopsylla mali (Schmidberger 1836) (an additional drawing of a separated sclerite 1Ax), b Aphis fabae (Scopoli 1763), c Orthezia urticae (Linnaeus 1758), d Aleyrodes proletella (Linnaeus 1758), dorsal view
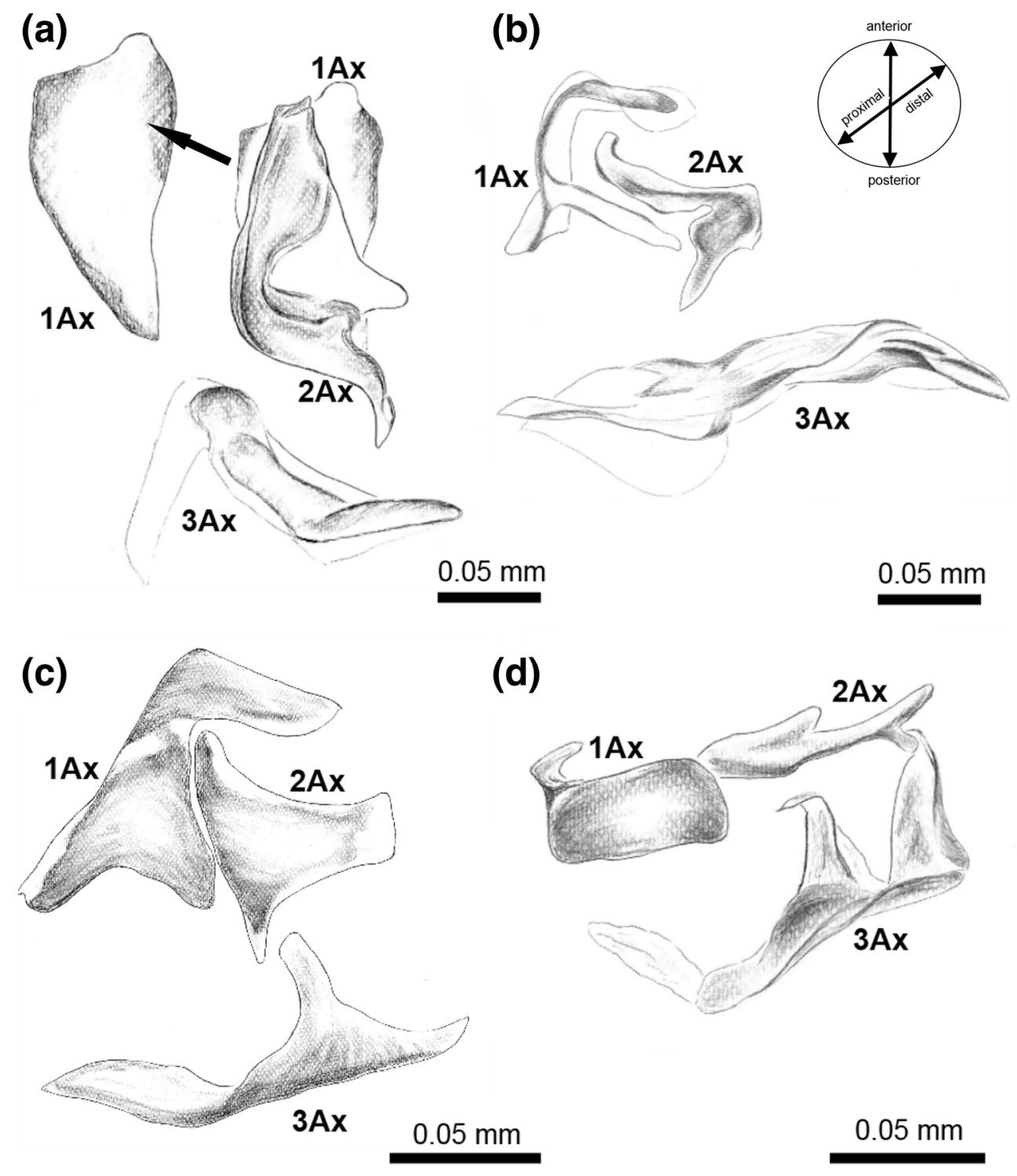

(a)

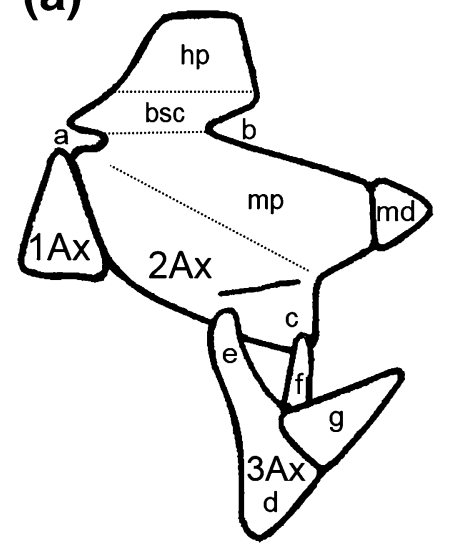

(b)

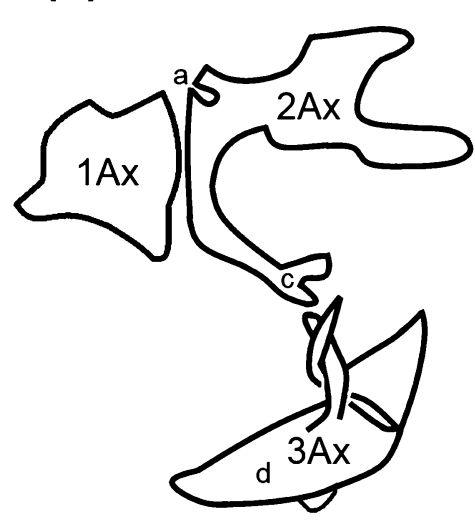

(c)

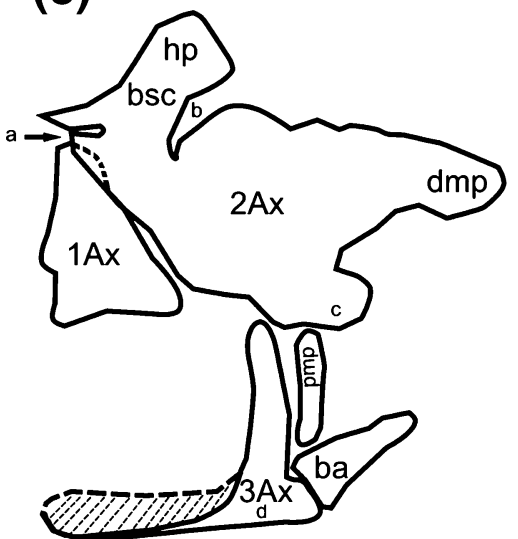

Fig. 7 Schematic drawings of axillary sclerites of Cixius nervosus (Linnaeus 1758) a modified, after Emeljanov 1977, b present interpretation, c Oliarus angusticeps (Horváth 1892) modified, after Yoshizawa and Saigusa (2001) 
(Fig. 7b). It is very difficult to see any homologies between outgrowths e and f form Emeljanov (1977) work and two appendages from present study. In our interpretation those two elements are twisted around each other and the whole $3 \mathrm{Ax}$ sclerite seems to be turned so only indication of differences is possible here.

\section{Connections between axillaries}

The general pattern of axillary sclerites is the same for all the examined Sternorrhyncha. The first sclerite joins anwp and $2 \mathrm{Ax}$; the second one is linked with $1 \mathrm{Ax}$ and distally is directed to the main, central vein; the third one is always connected with pnwp and with the wing membrane, near the anal vein. Nevertheless, the connections between axillary sclerites seem important. According to Yoshizawa and Saigusa (2001), in Cixiidae 1Ax is connected proximally to both anwp and mnwp and distally to $2 \mathrm{Ax}$. They only found a small gap between those two sclerites. According to Emeljanov (1977), all sclerites in the representative of Cixiidae are very closely connected as if they were fused. Our research confirmed the relation between 1Ax/notum and $1 \mathrm{Ax} / 2 \mathrm{Ax}$ as presented by Yoshizawa and Saigusa (2001) and also showed that between 1Ax and 2Ax there is a clearly visible space where the sclerites are connected to each other by a thin membrane (Figs. 4c, 7c). Because of the connection between $1 \mathrm{Ax}$ and anwp and mnwp, the arrangement of axillary sclerites in $C$. nervosus is most similar to the general pattern of wing articulation presented by Snodgrass (1935). The connection between $1 \mathrm{Ax}$ and $2 \mathrm{Ax}$, which are very close to each other in psyllids, was described by Ouvrard et al. (2008). Our observations confirm that report. Ouvrard et al. (2008) also noted the lack of connection between $2 \mathrm{Ax}$ and $3 \mathrm{Ax}$. Likewise, we are convinced that there is no sclerotized connection but only a membranous one. This is in contrast to Weber (1929) and Yoshizawa and Saigusa (2001), who did not indicate a separation between them. Besides, according to our study, both the first and second axillary sclerites have their origin in anwp, which is unusual in the examined Sternorrhyncha. Axillary $1 \mathrm{Ax}$ is hardly visible. The relations between three sclerites in $O$. urticae described by Koteja (1986) are similar to our results, i.e. $1 \mathrm{Ax}$ surrounds $2 \mathrm{Ax}$ and the latter is connected with $3 \mathrm{Ax}$.

The wing base in A. proletella is the hardest to interpret. As noted by Weber (1935), this part of the Aleyrodidae body is small and difficult to examine. Regardless, our results are not compatible with Weber's (1935): we could not confirm the presence of $4 \mathrm{Ax}$. After preparation, there seemed to be only a slightly sclerotized membranous part of $3 \mathrm{Ax}$ (Fig. 6d). In A. fabae there is an articulation between $2 \mathrm{Ax}$ and $3 \mathrm{Ax}$ and the latter proximally extends between the notum process and distally between $2 \mathrm{Ax}$ and the anal part of wing. However, the connection between $2 \mathrm{Ax}$ and $3 \mathrm{Ax}$ is not as pronounced as suggested by Weber (1928). These two sclerites are connected only by a thin membrane.

\section{Other elements of the forewing base}

The tegula is more or less variable but present in all the examined species. It has a globular form in $C$. mali, A. fabae and $A$. proletella or is a sclerite covering the wing base from the top as in $O$. urticae and $C$. nervosus. This sclerite is always covered by a few short hairs, even in $A$. proletella under the wax covering. In his work on morphology of Ortheziidae, Koteja (1986) pointed out that tegula is composed of two parts. According to our observations under the optical microscope, these are two different elements: the lower one is the tegula, covered by hairs and having clearly visible edges, and the upper one should be considered as parapterum (Fig. 3c). In turn, Weber (1935) reported $1 \mathrm{Po}_{2}$, in Aleyrodidae, which was a flat, frontal cushion on the front part of the lateral edge of the scutum. We could not identify such a structure in our studies. The second one, $2 \mathrm{Po}_{2}$, the rear cushion is, according to Weber (1935), identical with the tegula and we can consent to it. It is a domed part of the scutum over the wing base, so it can be interpreted as the tegula. A similar condition occurred in C. mali (Weber 1929), where two terms $\mathrm{Po}_{1}$ and $\mathrm{Po}_{2}$ were seen. In our study these are referred to parapterum and tegula, respectively. Muscle attachments, the subalare and basalare structures (Hörnschemeyer and Willkommen 2007), are visible only in the lateral view. Therefore, they could not have been recognized in our study in the dorsal aspect in A. proletella, O. urticae and C. mali, as indicated by Weber (1935), Koteja (1986) and Ouvrard et al. (2008), respectively. The humeral plate, located near the costal vein, is visible as a thickening or convexity and occurs in all the examined Sternorrhyncha species. Previously, it was reported only by Ouvrard et al. (2008) in psyllids. While describing $O$. urticae, Koteja (1986) wrote about "the costal complex", which, in our opinion, should rather be called a humeral plate. According to Emeljanov (1977), hp is fused with other elements that form 2Ax; also Yoshizawa and Saigusa (2001) indicated hp in Cixiidae (Fig. 7c). However, the occurrence of these elements could not be confirmed in our study. The distal and proximal median plates were for the first time described only for psyllids within Sternorrhyncha (Ouvrard et al. 2008); we found the former in A. fabae and $A$. proletella and the latter only in psyllids. The prealar bridge is only visible in C. mali; it is a long and narrow process extending downwards and slightly backwards to the mesoepisternum, as described Ouvrard et al. (2008). The connection of basiradiale with the distal median plate 
is wrapped around the central vein and referred to as a basiradial bridge; it is recognized in $O$. urticae and $A$. proletella. The parapterum, as mentioned above, is easy to find in $O$. urticae and $C$. mali-it is an extension situated above the tegula. The axillary cord (axc2) is recognizable in all the examined species. Previously, it was described only in Psyllomorpha by Ouvrard et al. (2008). The same authors pointed out that it was still doubtful whether pnwp belonged to the scutum or the scutellum. After Resh and Cardé (2003), the anterior notal wing process is defined as an anterior lobe of the lateral margin of the alinotum supporting $1 \mathrm{Ax}$, and the posterior notal wing process as a posterior lobe supporting $3 \mathrm{Ax}$. It seemed that pnwp constituted a part of the scutum. In our results, the posterior notal wing process is a part of the axillary cord and, accordingly, we have interpreted it as a part of the scutellum.

\section{Relationships inferred from the wing base structure}

There are four independent directions specific to each group. One noticeable tendency is that the first axillary sclerite, in all species, has a curved top outgrowth, which in Fulgoromorpha is not developed. The second and third axillary sclerites in A. fabae, A. proletella and C. mali differ in shapes among each other and are remarkably divergent from those in $C$. nervosus. The similarity in shape of each sclerite is most evident between the primitive coccid, $O$. urticae and $C$. nervosus. A small number of structures forming the environment of the wing base are alike as well. The species differ in: the shape of 1Ax (triangular with a curved tip in $O$. urticae and more trapezoid in $C$. nervosus), the shape and size of $2 \mathrm{Ax}$ (triangle in $O$. urticae and crooked in $C$. nervosus) and the structure of $3 \mathrm{Ax}$ (an elongated body of sclerite with one outgrowth in $O$. urticae and an elongated body with two curved outgrowths in $C$. nervosus). Coccids are known as the weakest flyers (Gullan and Martin 2009) so a highly advanced wing articulation is not necessary for them. They fold wings flat over the abdomen. The other species we examined fold their wings roof-like (synonym tent-like), but in A. fabae and $C$. mali we can see little apical overlap of the forewings. In $A$. proletella and $C$. nervosus, there is no apical overlap of the forewing so it looks like folding wings flat when in their resting position. It possibly explaining the different shape of the axillary sclerites in these species in comparison with those of O. urticae (Dolling 1991). Additionally, in $O$. urticae, A. proletella and $C$. nervosus, the second and third axillary sclerites are very close to each other and almost connected, which is also relevant to their wing position at rest.

We presented four different types of wing base morphology that can be compared to Sternorrhyncha molecular analyses phylogenies. The most common morphological view on Sternorryncha phylogeny recognizes a monophyletic group consisting of aphids + coccids and psyllids + aleyrodids as sister groups (Hennig 1981; Carver et al. 1991). Analyzing the layout of axillary sclerites (Fig. 6), we can risk the statement that the most similar sclerites are between aphids and coccids (Fig. 6b, c). It is likely that sclerites of $O$. urticae became more membranous with only edges strongly sclerotized and changed into elements occurring in A. fabae. Research on additional species of each group is required to adequately validate this hypothesis. On the other hand, analysis of Table 4 confirms all mentioned relations. Characters and their states collected in this table summarize the information about of axillary sclerites and connections between them. After detailed analysis, we can say that on the base of some features there is similarity between aphid + coccids and between psyllids + aleyrodids.

Based on results obtained by Ouvrard et al. (2008), we can conclude that the general plan of the wing base is specific for each group within Sternorrhyncha, but based on morphological features, we can try to infer the phylogenetic relationships.

Table 4 Axillary characters and their states in Sternorrhyncha infraorders

\begin{tabular}{|c|c|c|c|c|}
\hline & Psyllomorpha & Aphidomorpha & Coccomorpha & Aleyrodomorpha \\
\hline Anterior tip of $1 \mathrm{Ax}$ curved around anterior end of $2 \mathrm{Ax}$ & Not present & Present & Present & Not present \\
\hline $2 \mathrm{Ax}$ does not overlap $1 \mathrm{Ax}$ & False & True & True & True \\
\hline $3 \mathrm{Ax}$ with at least one outgrowth & Not present & Not present & $\begin{array}{l}\text { Present (with one } \\
\text { outgrowth) }\end{array}$ & $\begin{array}{l}\text { Present (with two } \\
\text { outgrowths) }\end{array}$ \\
\hline Tegula & Large, globular & Large, globular & Flat, small & Large, globular \\
\hline Humeral plate & Tubercle-like & Flat & Flat & Tubercle-like \\
\hline Parapterum & Tubercle-like & Not present & Flat & Not present \\
\hline Connection between $1 \mathrm{Ax} / 2 \mathrm{Ax}$ & Present & Present & Present & Present \\
\hline Connection between $2 \mathrm{Ax} / 3 \mathrm{Ax}$ & Not present & Not present & Present & Present \\
\hline
\end{tabular}


Acknowledgments The authors are sincerely grateful to Daniel Burckhardt and David Ouvrard for their helpful comments on the manuscript and special thanks to Colin Favret for checking linguistic correctness and valuable comments. We also wish to thank Justyna Płoszaj-Pyrek and Jagna Karcz SEM-Lab, University of Silesia, for their kind help during SEM sessions and to Jolanta Brożek and Łukasz Depa, University of Silesia, for suggestions and comments that have improved the manuscript.

Open Access This article is distributed under the terms of the Creative Commons Attribution 4.0 International License (http://crea tivecommons.org/licenses/by/4.0/), which permits unrestricted use, distribution, and reproduction in any medium, provided you give appropriate credit to the original author(s) and the source, provide a link to the Creative Commons license, and indicate if changes were made.

\section{References}

Afifi S, Kosztarab M (1967) Studies on the morphology and taxonomy of the males of Anatonina and related genus (Homoptera, Coccoidea, Pseudococcidae). Bull Va Polytech Inst State Univ 15:1-43

Becker-Migdisova EE, Aizenberg EE (1962) Infraotryad Aphidomorpha. [Infraorder Aphidomorpha]. 194-199. In: Rohdendorf BB (ed) Osnovy palontologii. Chlenistonogie. Trakheïnye i Khelicerovye. [Fundamentals of Palaeontology. Arthropoda. Tracheata and Chelicerata.] 9. Izdatel'stvo Akademii Nauk SSSR, Moscow. Published in English as: Becker-Migdisova EE, Aizenberg EE (1991). Infraorder Aphidomorpha. In: Rohdendorf BB (ed) Fundamentals of paleontology. Arthropoda, Tracheata and Chelicerata, vol 9, pp 218-289 (General Editor English Trans: Davis DR Smithsonian Institution Libraries and The National Science Foundation, Washington, DC pp 1-894)

Béthoux O (2007) Archaeorthoptera wing venation nomenclature: a reply to Gorokhov. Paleontol J 41(3):338-340

Béthoux O, Nel A (2001) Venation pattern and revision of Orthoptera. J Orthoptera Res 10(2):195-198

Béthoux O, Nel A (2002) Venation pattern and revision of Orthoptera sensu nov. and sister groups: phylogeny of Paleozoic and Mesozoic Orthoptera sensu nov. Zootaxa 96:1-88

Brodsky AK (1996) The evolution of insect flight. Oxford University Press, New York, Tokyo

Carver M, Gross GF, Woodward TE (1991) Hemiptera (bugs, leafhoppers, cicadas, aphids, scale insects etc.). In: CSIRO (ed) The insects of Australia. A textbook for students and research workers, vol 1, 2nd edn. Melbourne Univ Press, Carlton, p 429

Chapman RF (2013) The insects: structure and function, 5th edn. Cambridge University Press, Cambridge

Chou I (1963) Some viewpoints about insect taxonomy. Acta Entomol Sin 12:586-596

Comstock JH, Needham JG (1898) The wings of insects. Am Nat 32(373):43-48

Dolling WR (1991) The Hemiptera. Oxford University Press, New York

Emeljanov AF (1977) Homology of wing structures in Cicadina and primitive Polyneoptera. Terminology and homology of venation in insects. Trudy Vses Entomol Obshchestva 58:3-48 [in Russian]

Field LH, Matheson T (1998) Chordotonal organs in insects. Adv Insect Physiol 27:1-230

Gullan PJ, Martin JH (2009) Sternorrhyncha (jumping plant-lice, whiteflies, aphids, and scale insects). In: Resh VH, Cardé RT (eds) Encyclopedia of insects, 2nd edn. Elsevier, San Diego, pp 957-967
Hamilton KGA (1972) The insect wing, part IV. Venational trends and the phylogeny of the winged orders. J Kans Entomol Soc 45(3):295-308

Hennig W (1981) Insect phylogeny. Wiley, New York

Heslop-Harrison G (1952) The number and distribution of the spiracles of the adult psyllid. Ann Mag Nat History 12:248-260

Hörnschemeyer T (2002) Phylogenetic significance of the wing-base of the Holometabola (Insecta). Zool Scr 31:17-29

Hörnschemeyer T, Willkommen J (2007) The contribution of flight system characters to the reconstruction of the phylogeny of the Pterygota. Arthropod Syst Phylo 65(1):15-23

Klimaszewski S, Wojciechowski W (1993) Relationships of recent anf fossil groups of Sternorrhyncha as indicated by the structure of their forewings. Prace Nauk Uniw Slask Katow 1318:1-50

Koteja J (1986) Morphology and taxonomy of male Ortheziidae (Homoptera, Coccinea). Pol Pismo Entomol 56:323-374

Koteja J (1996) Scale insects (Hemiptera: Coccinea) a day after. In: Schaefer CW (ed.) Studies on Hemipteran phylogeny. Thomas Say Publications in Entomology: Proceedings of Entomological Society of America, Lanham, MD pp 65-88

Kukalovà-Peck J (1978) Origin and evolution of insect wings and their relation to metamorphosis, as documented by the fossil record. J Morph 156:53-126

Kukalovà-Peck J (1991) Fossil history and the evolution of hexapod structures. In: Naumann ID, CSIRO (eds) The insects of Australia, 2nd edn. Malbourne University Press, Melbourne, pp 141-179

Martin JH (2007) Giant whiteflies (Sternorrhyncha, Aleyrodidae): a discussion of their taxonomic and evolutionary significance, with the description of a new species of Udamoselis Enderlein from Ecuador. Tijdschr Entomol 150:13-29

Nel A, Prokop J, Nel P, Grandcolas P, Huang D-Y, Rogues P, Guilbert E, Dostál O, Szwedo J (2011) Traits and evolution of wing venation pattern in Paraneopteran insects. J Morphol 273(5):480-506. doi:10.1002/jmor.11036

Ninomiya T, Yoshizawa K (2009) A revised interpretation of the wing base structures of Odonata. Syst Entomol 34:334-345

Ouvrard D, Burckhardt D, Soulier-Perkins A, Bourgoin T (2008) Comparative morphological assessment and phylogenetic significance of the wing base articulation in Psylloidea (Insecta, Hemiptera, Sternorrhyncha). Zoomorphology 127:37-47. doi:10. 1007/s00435-007-0049-x

Patch EM (1909) Homologie of the wing veins of the Aphididae, Psyllidae, Aleyrodidae and Coccidae. Ann Entomol Soc Am 2:101-135

Rasnitsyn AP (1981) A modified paranotal theory of the insect wing origin. J Morphol 168:331-338

Resh VH, Cardé RT (2003) Encyclopedia of insects. Academic Press, San Diego

Shcherbakov DE (2007) Extinct four-winged precoccids and the ancestry of scale insects and aphids (Hemiptera). Russ Entomol J 16(1):47-62

Simon E (2013) Preliminary study of wing interference patterns (WIPs) in some species of soft scale (Hemiptera, Sternorrhyncha, Coccoidea, Coccidae). Zookeys 319:269-281. doi:10.3897/ zookeys.319.4219

Snodgrass RE (1935) Principles of insect morphology. McGraw-Hill Book Company Inc., New York

Song N, Liang A-P (2013) A preliminary molecular phylogeny of planthoppers (Hemiptera: Fulgoroidea) based on nuclear and mitochondrial DNA sequences. PLoS ONE 8(3):e58400. doi:10. 1371/journal.pone.0058400

Song N, Liang A-P, Bu C-P (2012) A molecular phylogeny of Hemiptera inferred from mitochondrial genome sequences. PLoS ONE 7(11):e48778. doi:10.1371/journal.pone.0048778 
Weber H (1928) Skelett, Muskulatur und Darm der Schwarzen Blattlaus Aphis fabae SCOP. Zoologica 76:1-120

Weber H (1929) Kopf und Thorax von Psylla mali SCHMIDB. (Hemiptera-Homoptera). Eine morphogenetische Studie. Z Morphol Tiere 14:59-165

Weber H (1935) Der Bau der Imago der Aleurodinen. Ein Beitrag zur vergleichenden Morphologie des Insektenkorpers. Zoologica 89. E. Schweizerbart'sche Verlagsbuchhandlung (Erwing Nagele). Stuttgart

Wootton RJ (1996) Functional wing morphology in Hemiptera systematics. In: Schaefer CW (ed) Studies in Hemiptera phylogeny. Entomological Society of America, Lanham, pp 179-198
Wootton RJ (2002) Design, function and evolution in the wings of holometabolous insects. Zool Scr 31:31-40

Wootton RJ, Kukalová-Peck J (2000) Flight adaptations in palaeopterous insects. Biol Rev 75:129-167

Yoshizawa K (2011) Monophyletic Polyneoptera recovered by wing base structures. Syst Entomol 36:377-394

Yoshizawa K, Saigusa T (2001) Phylogenetic analysis of paraneopteran orders (Insecta:Neoptera) based on forewing base structure, with comments on monophyly of Auchenorrhyncha (Hemiptera). Syst Entomol 26:1-13. doi:10.1046/j.1365-3113. 2001.00133.x 